INNOVATION AND IMPROVEMENT

\title{
Interval Examination: Moving Toward Open Notes
}

\author{
Jan Walker, RN, MBA and Tom Delbanco, MD, MACP \\ BIDMC Division of General Medicine \& Primary Care, Harvard Medical School, Boston, MA, USA.
}

KEY WORDS: patient engagement; health care administration; health information technology; electronic medical records.

J Gen Intern Med 28(7):965-9

DOI: $10.1007 / \mathrm{s} 11606-013-2407-3$

(c) Society of General Internal Medicine 2013

$\mathrm{D}$ espite periodic efforts over almost 5 decades, the idea of having patients review and contribute to their medical records has failed to take hold, even though such practice might engage patients more actively in maintaining their health and managing their care and might also improve quality of care and patient safety. Contemporary trends toward increased transparency, accompanied by evolving health information technologies, provided an opportunity for us to conduct a study examining the effects on both patients and primary care physicians (PCPs) of inviting patients to read their doctors' visit notes. Bolstered by encouraging findings from this study, and with the goal of informing those who might join in further inquiry, we outline in this "interval examination" challenges we are encountering and strategies we are employing as we explore wider implementation of this practice.

\section{ROOTS}

The groundwork was established more than 40 years ago. Lawrence Weed wrote in 1968 that, "Physicians must assume the leadership in providing each patient with a total list of problems, irrespective of who in the medical hierarchy provided the data, and in seeing that therapeutic action reflects some perspective on the total needs of the patient." In 1972, Warner Slack predicted that, "The medical chart, traditionally closed to the patient, will be declassified at last and become a document developed jointly by patient and doctor." 2 And in 1973, Shenkin and Warner challenged the medical community in a "Sounding Board" in the New England Journal of Medicine: "Giving the patient his medical record: a proposal to improve the system." 3

Received December 27, 2012

Revised February 20, 2013

Accepted February 22, 2013

Published online April 26, 2013
In the years since these proposals, the medical record evolved to suit primarily the needs of clinicians, administrators, and insurers. Legal ownership of the medical record, which rested with providers, posed additional barriers to increasing transparency, and requests for copies often involved forms, wait times, and copying costs. Nevertheless, efforts to modify the longstanding top-down doctor-patient relationship began to gain currency. In the 1980s, studies suggested that teaching patients to be more aggressively involved in their care can lead to improved clinical outcomes. ${ }^{4-6}$ The "patientcentered care" movement argued that providers could learn in a systematic way from patient reports about their experiences and could improve care by looking "through the patient's eyes." ${ }^{" 7,8}$ Champions of "shared decision-making" advocated moving care toward a more "level playing field." finally, in 1996, HIPAA, perhaps reflecting growing strength among consumer movements, granted virtually all patients access to their records. ${ }^{13}$

If facilitating medical record transparency might improve patient care, and individuals have the legal right to review their records, why not make it easy for them to do so? Might reviewing their doctor's notes help them engage more actively in their care? With the growth of health information technology, small experiments with open records began. ${ }^{14-16}$ Researchers targeted chronic disease management and found improvements in care plan adherence with the assistance of online medical records. These positive findings encouraged us to mount a larger study.

\section{AN INITIAL FORAY INTO PRIMARY CARE}

We implemented "open notes" in three widely disparate sites: (1) an urban academic health center, Beth Israel Deaconess Medical Center (BIDMC), with hospital-based and community-based practices in and around Boston, (2) primarily rural practices in Pennsylvania associated with the Geisinger Health System (GHS), and (3) general medicine and HIV practices at Harborview Medical Center (HMC), the safety net county hospital in Seattle. In brief, targeting about 20,000 of their patients who had registered on secure, electronic patient portals, 105 primary care physicians (PCPs) volunteered to invite them to review notes signed following visits. Using administrative data and surveys before and after the intervention, we focused on three 
overall questions: (1) Would patients choose to read their notes, and would they report benefits from the experiences? (2) Would doctors' fears about frightening patients and disruptions to their workflow be realized? (3) And, at the end of a year's experience with open notes, how would doctors and patients "vote" about continuing the practice?

We have described the rationale and methodology for the study, the expectations of both PCPs and their patients prior to the start of the study, and the overall results of the project in a series of recent papers. ${ }^{17-20}$ In brief, we learned that patients were enthusiastic about the experience and reported potentially important clinical benefits, such as improved recall and understanding of their care plan, improved adherence to their medications, and feeling more in control of their care. We found that doctors were surprised by how few patients appeared troubled by what they read and how little effect the intervention had on the PCPs' work lives. Finally, both the patients and their PCPs voted to continue the practice; $99 \%$ of patients wanted the practice to continue, and when offered the opportunity to stop at the end of the first year of the intervention, not one PCP chose to do so.

\section{THE CASE FOR EXPANDING BEYOND THE PILOT PROGRAM}

The primary care patients and doctors who participated in the first open notes project provided many comments and insights. We distilled them into a series of arguments for broad adoption of fully open records:

\section{- Patient activation}

Before we started, we approached Glenn Steele, CEO of Geisinger, to see if he would agree to encourage PCPs in their integrated health system to join the open notes experiment. A distinguished surgeon, Dr. Steele had two quick, surgical responses. In contrast to a wide range of clinical pathways that appeared to improve quality and contain costs that GHS had implemented, ${ }^{21-23}$ he felt they did not have a robust strategy for increasing patient engagement. For that, he believed open notes held considerable promise, and he was eager to learn what GHS patients would experience. His second point was equally clear: If this intervention proved a negative experience for his doctors caring for large panels of patients, open notes would be out the door at the end of the year.

Two years later, Steele was convinced: "For us, it was the next step: taking the care-giving from us being active and patients being passive, to patients being active and us being mentors. Overall, it's transformational. ${ }^{24}$
- Patient safety

Adding a new set of eyes to review clinicians' notes may promote safety, as patients correct or amplify family histories and allergic reactions, point to errors or misunderstandings about medications, and help identify and correct diagnostic and therapeutic errors of commission and omission, hopefully before harm ensues. In 5,568 surveys completed by patients who had visits during the study, several offered examples of errors they discovered, citing both mistakes made by themselves (e.g., not following up on a referral) and mistakes made by their doctors (e.g., not ordering a planned test). The potential for improving quality and safety clearly carried weight as we discussed with both advocates and skeptics whether or not to move forward.

\section{- Efficient use of health services}

I read your "open notes" in preparation for my check-up next week, and I'm quite sure nothing has changed ... I'm feeling fine, still working out...rash is still gone, etc. Shall I reschedule for 3-6 months, or do you still want me to come in? (e-mail message from a patient to a PCP)

Active patient involvement may lead to more efficient care, with visits at longer intervals, fewer missed appointments, and improved priority setting by both patients and clinicians. Where appropriate, the potential for fully transparent records to help move care from the hospital or clinician's office into the home has broad implications for the future. It will be difficult to develop data that demonstrate whether and how changes in utilization relate to transparency, communication, and patient involvement, but comments like this one point to potential efficiencies.

\section{- Market advantage}

For providers in competitive environments and the transparency of open medical records may provide a market advantage. With $99 \%$ of patients in the study voting that open notes continue, $85 \%$ stating that their presence will affect their future choice of provider or health system, and apparent public interest based on widespread media coverage of this study, we anticipate that institutions will advertise fully open records as supporting evidence for their 'patient-centered care.' In the crowded Boston marketplace, for example, such argument may carry weight.

- Meaningful Use (MU)

Many institutions and clinicians are scrambling to meet escalating requirements for "meaningful use" of electronic medical records. ${ }^{25}$ While we do not know how exactly open 
notes will relate to $\mathrm{MU}$, implementing open notes could boost patients' interest in online records and help organizations meet evolving MU requirements to offer patients electronic access.

\section{- A "new medicine"}

We talk about open notes as a "new medicine." As is the goal for all new therapies, open notes will likely benefit many patients, while having relative and absolute contraindications for only a few. We urge clinicians to join patients in refining its formulation and learning how to maximize its utility and minimize its potential harms.

\section{AN INSTITUTION DECIDES TO ADOPT OPEN NOTES}

Armed with these data and themes, we asked clinicians and executives at the three sites to consider expanding adoption of fully transparent records. The process at BIDMC offers an example.

We began by presenting study findings informally to individual BIDMC clinical leaders, front line PCPs, patients, and senior executives, including the CEO. We were then invited to present the findings and offer recommendations to the hospital's Clinical Executive Operations Committee, led by the $\mathrm{CEO}$ and composed of senior administrators and all department chiefs.

They voted whether to 1) reject open notes, 2) study them further, 3) expand to clinicians who "opt in," 4) expand to all clinicians unless they "opt out" with their department chiefs, or 5) expand to all clinicians without exception.

With encouragement of the CEO, the Committee voted unanimously for option 4 . In a phased rollout beginning in Spring 2013, unless granted an exemption by their chiefs, all BIDMC clinicians who write and sign electronic encounter notes in the EMR will open their outpatient, and then inpatient notes on the patient portal. This includes all attending physicians, house staff and fellows, nurses, nurse practitioners, physician assistants, social workers, clinical pharmacologists, and physical and occupational therapists.

Some exceptions will exist: At least initially, notes written by students will not be opened. Only notes composed after the new policy goes into effect will be opened. Inpatient notes that reside in a system different from the main EMR will not be opened. And, in a longstanding practice used primarily by mental health providers, clinicians will have the option of writing a "monitored" note that is blinded to the patient online and requires an explicit reason before other clinicians may read it. In the long run, we anticipate that such notes will be divided into two categories: (1) those that the patient and provider agree are best not visible to the patient, and (2) "private" commentary between and among clinicians caring for a patient.

\section{OPERATIONAL AND POLICY IMPLICATIONS}

GHS and HMC have also decided to expand open notes. At this time of writing, HMC is evolving a wide-spread rollout, and more than 600 physicians at GHS plan to open their ambulatory care notes in Spring 2013.

While introducing open notes requires attention to organization-specific questions about policy and implementation, many institutions will face questions in common. For example, should embargoes for laboratory, radiology, and pathology reports be modified in the presence of open notes? ${ }^{26,27}$ How will we address challenges posed by clinicians who do not write or sign notes in a timely way, inconsistencies between what a clinician writes and what a patient may recall, and communications with patients who may uncover troublesome test findings? Though the volume of e-mail traffic did not change for PCPs in our study, how should calls and e-mail messages from patients be routed if patients raise questions about their notes? A third of patients returning surveys in our study felt they should be able to have notes changed; what rules should govern amendments? How should disagreements about sharing notes between clinicians and individual patients be resolved? Should clinicians be allowed to exclude specific patients? How can one facilitate efficient communication among patients, families, and providers? What about care sites without EMRs, or those without patient portals? Will they join this practice by sharing paper copies of notes with their patients?

Expanding the use of patient portals also raises many questions: How to motivate and encourage both patients and clinicians to use them is no small challenge in itself. And with access to notes, patients exercise more control over the privacy of their information; how will that intersect with the time-honored confidentiality of the patient-clinician relationship? Indeed, 20 to $45 \%$ of patients in our study chose to share their notes with family members or others, and we expect those numbers will grow. Should proxy access to notes be any different from access to other parts of the record? What resources will be required to implement such functions?

\section{EXPLORING NEW TERRAIN}

Many further opportunities derive from these early experiences. For example, while working with one of her medical students, an internist and open notes participant at BIDMC decided that instead of drafting a note herself, she would have the student write the note and then ask the patient to review it; she found the process benefitted both the patient and the student. Patients could join faculty in critiquing notes drafted by students at all levels of training, with particular attention to highly 
charged topics, such as cancer, obesity, mental health, and substance abuse. As patients and students convene around the note, join in assessing data, articulate perceptions and preferences, and agree on treatment plans, we anticipate substantial educational benefits.

We expect that opening notes in the office practices of subspecialists, residents, and clinicians other than doctors will not prove all that different from our experience in the primary care setting. Indeed, many consulting physicians have long had the habit of sending patients a copy of their letters to the physician seeking consultation. But how open notes will translate to the emergency unit, hospital room, or intensive care unit poses new challenges and attendant need for careful inquiry. To start, consider the rapid pace of change and decisions that accompany emergently ill patients, the variety of clinicians convening around patients with constantly shifting clinical challenges, and the complexity of transitions both during hospitalization and to other settings. Inpatient doctors, trainees, consultants, nurses, social workers, and rehabilitation specialists will need to develop entirely new reflexes as teams join patients and their families in convening around a newly transparent record. BIDMC anticipates that such practice will inure to the overall benefit of patients, but just how to achieve this goal remains largely unexplored.

And many further questions beckon. Two-thirds of patients in our study reported taking medications more effectively; do they really change the way they adhere to their medications and treatment plans? How will what clinicians write change, and can one record serve multiple audiences? ${ }^{17}$ Can sharing notes reduce morbidity among family caregivers, particularly when their parents or partners near the end of life? How might open notes evolve for patients in a rehabilitation facility, in long-term care, and perhaps most importantly, for those ill at home?

\section{IN CONCLUSION}

Using both quantitative and qualitative techniques, we plan to document the implementation process in our institutions, so that others can learn from our experience and bypass our mistakes. Energized by the findings from our first inquiry, we plan to continue our research and turn increasingly to advocacy (www.myopennotes.org). We expect that fully open medical records will become the standard of care and that such transparency will strengthen communication, involve patients more actively in their health and illness, improve safety, and enhance the quality of care.

ACKNOWLEDGMENTS: We thank Melissa Anselmo, MPH, Roanne Mejilla, MPH, and Sigall Bell, MD, who contributed assistance and editorial advice. This work was supported by the Robert Wood Johnson Foundation's Pioneer Portfolio grant \#69488, the Drane Family Fund, and the Richard and Florence Koplow Charitable Foundation.

Disclaimer: OpenNotes ${ }^{\circledR}$ is not a software program. OpenNotes ${ }^{\circledR}$ is an initiative that invites patients to review their visit notes written by their doctors, nurses, or other clinicians.

Conflict of Interest: Ms. Walker reports no conflicts. Dr. Delbanco holds stock options in Eliza Corp.

Corresponding Author: Jan Walker, RN, MBA; BIDMC Division of General Medicine \& Primary Care, Harvard Medical School, 1309 Beacon St, 2nd floor, Boston, MA 02446, USA (e-mail: Jwalker1@bidmc.harvard.edu).

\section{REFERENCES}

1. Weed LL. Medical records that guide and teach. N Engl J Med. 1968;278(12):652-7.

2. Slack WV. Patient Power: A patient-oriented value system. In: Jacquez JA, ed. Computer Diagnosis and Diagnostic Methods. Proceedings of the Second Conference on the Diagnostic Process health at the University of Michigan. Springfield, IL: Charles C. Thomas, 1972:3-7.

3. Shenkin BN, Warner DC. Giving the patient his medical record: a proposal to improve the system. N Engl J Med. 1973;289(13):68892.

4. Greenfield S, Kaplan S, Ware JE Jr. Expanding patient involvement in care. Effects on patient outcomes. Ann Intern Med. 1985;102(4):5208

5. Holman H, Lorig $\mathbf{K}$. Patient education in the rheumatic diseases-pros and cons. Bull Rheum Dis. 1987;37(5):1-8.

6. Lorig $\mathbf{K}$, Holman HR. Long-term outcomes of an arthritis self-management study: effects of reinforcement efforts. Soc Sci Med. 1989;29(2):221-4.

7. Delbanco TL. Enriching the doctor-patient relationship by inviting the patient's perspective. Ann Intern Med. 1992;116(5):414-8.

8. Gerteis M, Edgman-Levitan S, Daley J, Delbanco T, eds. Through the Patient's Eyes: Understanding and Promoting Patient-Centered Care. San Francisco: Jossey-Bass Publishers; 1993.

9. Coulter A. Do patients want a choice and does it work? BMJ. 2010;341.

10. Cooper $\mathbf{L}$, Roter $\mathbf{D}$, Carson $\mathbf{K}$, et al. A randomized trial to improve patient-centered care and hypertension control in underserved primary care patients. J Gen Intern Med. 2011;26(11):1297-304.

11. Roter DL, Larson S, Sands DZ, Ford DE, Houston T. Can E-mail messages between patients and physicians be patient-centered? Health Commun. 2008;23(1):80-6.

12. Cooper LA, Roter DL, Johnson RL, Ford DE, Steinwachs DM, Powe NR. Patient-centered communication, ratings of care, and concordance of patient and physician race. Ann Intern Med. 2003;139(11):90715.

13. Department of Health and Human Services. Standards for privacy of individually identifable health information. Billing Code 4150-04 M (45 CFR Parts 160-164) ed: Federal Register. 2000; 82461-829.

14. Ross SE, Moore LA, Earnest MA, Wittevrongel L, Lin CT. Providing a web-based online medical record with electronic communication capabilities to patients with congestive heart failure: randomized trial. J Med Internet Res. 2004;6(2):e12.

15. Earnest MA, Ross SE, Wittevrongel L, Moore LA, Lin CT. Use of a patient-accessible electronic medical record in a practice for congestive heart failure: patient and physician experiences. J Am Med Inform Assoc. 2004;11(5):410-7.

16. Ralston JD, Revere D, Robins LS, Goldberg HI. Patients' experience with a diabetes support programme based on an interactive electronic medical record: qualitative study. BMJ. 2004;328(7449): 1159.

17. Delbanco T, Walker J, Darer JD, et al. Open notes: doctors and patients signing on. Ann Intern Med. 2010;153(2):121-5. 
18. Walker J, Leveille SG, Ngo L, et al. Inviting patients to read their doctors' notes: patients and doctors look ahead: patient and physician surveys. Ann Intern Med. 2011;155(12):811-9.

19. Delbanco T, Walker J, Bell SK, et al. Inviting patients to read their doctors' notes: a quasi-experimental study and a look ahead. Ann Intern Med. 2012;157(7):461-70.

20. Leveille SG, Walker J, Ralston JD, Ross SE, Elmore JG, Delbanco T. Evaluating the impact of patients' online access to doctors' visit notes: designing and executing the OpenNotes project. BMC Med Inform Decis Mak. 2012;12:32.

21. Maeng DD, Graham J, Graf TR, et al. Reducing long-term cost by transforming primary care: evidence from Geisinger's medical home model. Am J Manag Care. 2012;18(3):149-55.

22. Paulus RA, Davis K, Steele GD. Continuous innovation in health care: implications of the Geisinger experience. Health Aff (Millwood). 2008;27(5): 1235-45.
23. Steele GD, Haynes JA, Davis DE, et al. How Geisinger's advanced medical home model argues the case for rapid-cycle innovation. Health Aff (Millwood). 2010;29(11):2047-53.

24. Robert Wood Johnson Foundation. OpenNotes: health care leaders speak out. 4 mins 56 s. Available at http://www.youtube.com/watch? $\mathrm{v}=2$ idRPIkHL8c.

25. HealthIT.gov. Step 5: achieve meaningful use [cited 2012 December 26]; Available at http://www.healthit.gov/providers-professionals/ehrimplementation-steps/step-5-achieve-meaningful-use.

26. Johnson AJ, Easterling D, Nelson R, Chen MY, Frankel RM. Access to radiologic reports via a patient portal: clinical simulations to investigate patient preferences. J Am Coll Radio. 2012;9(4):25663.

27. Rodriguez E, Thom B, Schneider S. Nurse and physician perspectives on patients with cancer having online access to their laboratory results. Oncol Nurs Forum. 2011;38(4):476-82. 